\title{
História de um país invadido: pantanais entre Bororo, brasileiros, belgas e platinos (1870-1912)
}

\section{History of an invaded country: The Pantanal wetlands between Bororo, Brazilians, Belgians and People from the Plata River (1870-1912)}

\author{
Alexia Helena Araujo* \\ José Augusto Pádua*
}

\begin{abstract}
Resumo
A segunda metade do século XIX trouxe grandes mudanças aos espaços mais ocidentais do Estado brasileiro: territórios não apropriados pelo paradigma moderno e capitalista tornaram-se alvos de projetos nacionais, comerciais, industriais. Na perspectiva de governantes, políticos e estadistas que formulavam remotamente as diretrizes para ocupação dos sertões, a natureza era vista sobretudo como recurso para o desenvolvimento econômico da "nação". Vastas áreas de pantanais seriam, então, incorporadas ao território mato-grossense e brasileiro, através do mapeamento, da implementação de redes de transporte e comunicação e da instituição da propriedade moderna. Não obstante, as populações nativas, orientadas por lógicas diversas, rejeitariam as imposições desse novo paradigma, tentando manter o domínio sobre suas terras e suas comunidades. O presente artigo busca analisar transformações e conflitos ocorridos nesse desencontro entre povos locais, capitais e Estado nacional. Em campos e pantanais do Alto Paraguai, os Bororo Ocidentais enfrentariam, na transição entre o século XIX e XX, a ânsia colonialista da corporação Cibils que se associaria a órgãos e instituições estatais para impor violentamente formas específicas de interação com a natureza.
\end{abstract}

Palavras-chave: Capitalismo; Bororo; Pantanais.

\section{Abstract}

The second half of the nineteenth century brought big changes to the western spaces of the Brazilian State: territories which hadn't been yet appropriated by

\footnotetext{
"Doutora em História Social pela Universidade Federal do Rio de Janeiro. E-mail: alexiahelena@gmail.com ** Doutor em Ciência Política pelo IUPERJ. Professor do Instituto de História da Universidade Federal do Rio de Janeiro.E-mail: japadua@terra.com.br
} 
the modern and capitalist paradigm became the object of national, commercial and industrial projects. From the perspective of politicians, governments and statesmen, who remotely formulated the guidelines for the occupation of wilderness, nature was seen, above all, as a resource for the economic development of the nation. Vast areas of pantanais would be then, incorporated into Mato Grosso and Brazilian territories through mapping, establishment of transports and communication networks and the institution of modern property rights. Nevertheless, native populations, driven by different logics, rejected the impositions of these new paradigms, trying to keep their dominium over their lands and communities. This paper seeks to analyze transformations and conflicts that occurred in this confrontation between local peoples, capitals and national state. In the immense fields and wetlands of Upper Paraguay River, the Western Bororo would confront the colonialist urge of the Cibils Company which would associated itself to state agents and institutions in order to violently impose specific forms of interaction with nature.

Keywords: Capitalism; Bororo; Pantanais.

\section{As margens do rio Paraguai}

Rios, corixos, pantanais, lagoas... um labirinto aquático entremeado de capões, campinas, bosques e afloramentos. Aroeiras, buritis, carandás, cambarás, acanguçus, araras, tuiuius, sucuris... ${ }^{1}$ Em meio à marcante diversidade ecológica, comunidades humanas resistiam aos avanços colonialistas que tantas mudanças vinham trazendo às dinâmicas locais. ${ }^{2}$ Apesar das grandes transformações por que passara o continente sul-americano ao longo do XIX,

\footnotetext{
${ }^{1}$ Os nomes de árvores e animais citados são indígenas, sobretudo tupi. Ainda que não se tenha encontrado nenhuma referência, o termo Aroeira pode ter origem Bororo, uma vez que em cerimônias fúnebres, os Aroes (cujo significado seria algo próximo a alma) usam os esteios de madeira, comumente feitos de aroeira, como passagem à nova morada. As etimologias dos nomes de árvores e animas foram pesquisadas em alguns dicionários virtuais como o Dicionário Tupi-Guarani (https://www.dicionariotupiguarani.com. br), o Dicionário Brasileiro da Língua Portuguesa (http://michaelis.uol.com.br/moderno-portugues/) e o Herbário Prof. Jorge Pedro Pereira Carauta - HUNI (http://www.unirio.br/ccbs/ibio/herbariohuni).

${ }^{2}$ Usamos a acepção de Boaventura de Sousa Santos de colonialismo como "todo o modo de dominação assente na degradação ontológica das populações dominadas por razões etno-raciais". Dessa maneira, ao referir-nos aos avanços colonialistas, não estamos nos restringindo ao período colonial, mas estendendo-nos ao período de expansão capitalista, entre fins do século XIX e início do século XX. (SANTOS, B. S. "O colonialismo e o século XXI". Outras palavras, São Paulo, 2 abr. 2018. Disponível em: <https://outraspalavras.net/geopoliticaeguerra/boaventura-o-colonialismo-e-o-seculo-xxi/>. Acesso em 10 mar. 2020).
} 
o Pantanal norte chegava ao fim do século como um vasto sertão. ${ }^{3}$ Os escassos núcleos brasileiros eram ainda envoltos por um oceano de comunidades indígenas e quilombolas.

O momento, porém, trazia novos reveses às populações que buscavam se manter autônomas. A economia capitalista, em movimento de expansão por territórios periféricos, contava agora com novas e modernas tecnologias, como vapores e telégrafos, além de armas de fogo industriais. Novos atores sociais, atraídos pela perspectiva de opulentos ganhos em espaços "virgens", 5 associaram-se às instituições governamentais brasileiras para implementar projetos comerciais, industriais, infraestruturais.

"Sob a ótica da administração pública, a defesa de grandes companhias, politicamente se justificava pelas receitas geradas" e também por razões de ordem estratégica. ${ }^{6}$ As empresas garantiam controle territorial, construíam estradas, exploravam territórios e reconheciam virtualmente, na esfera internacional, a soberania brasileira sobre aqueles espaços. O Estado fortalecia sua autoridade nacional, recolhia impostos e consolidava-se como árbitro e legitimador de disputas fundiárias, assegurando aos capitalistas, as condições de exploração do trabalho. A colonização cobraria altos custos dos povos locais. Comunidades indígenas seriam dizimadas, escravizadas e deslocadas num processo que reverbera suas consequências ainda hoje.

Considerados como "uma das bases étnicas da atual população mato-grossense", 7 os Bororo, se espalhavam "numa área maior de 48.000.000 de hectares", ${ }^{8}$ entre Goiás e Bolívia, entre o rio Miranda e os formadores do

\footnotetext{
${ }^{3}$ Cf. MORAES, A. C. O Sertão: um outro geográfico. Terra Brasilis, Rio de Janeiro, v. 4-5, p. 11-23, 2003. Disponível em: <http://terrabrasilis.revues.org/341>. Acesso em: 15 fev. 2020.

${ }^{4}$ Ângela Santos e Maria Muller identificaram registros de 9 comunidades quilombolas entre Cáceres e Vila Bela. (SANTOS, A. M. e MULLER, M. L. R. Narrativas e memória sobre a comunidade quilombola Exú. In: VII Congresso Internacional de Pesquisa (Auto)Biográfica, Cuiabá, 2016. Anais...Cuiabá: UFMT, 2016).

${ }^{5}$ Evocamos a construção mítica da natureza virgem como justificativa para o projeto de incorporação de territórios selvagens ao sistema-mundo. Nesse sentido, os adjetivos virgem e selvagem relacionam-se, não à falta de ação humana sobre o espaço, mas à falta de ação humana qualificada nas concepções colonialistas. Cf. DIEGUES, A. C. 0 mito moderno da natureza intocada. 6 ed. Rev.e Amp. São Paulo: HUCITEC; NUPAUB, 2008 e SHELLARD, D. História, meio ambiente e interdisciplinaridade. Hist. R., Goiânia, v. 22, n. 2, p. 23-44, mai./ago. 2017. Sobre sistema-mundo, cf. WALLERSTEIN, I. The modern world-system IV: centrist liberalism triumphant, 1789-1914. Berkeley: University of California Press, 2011.

${ }^{6}$ TRUBILIANO, C. A. B. Algumas considerações sobre a Ferrovia Noroeste do Brasil: migração e ocupação em Campo Grande MT/MS (1905-1940). MÉTIS, Caxias do Sul, v. 14, n. 27, p. 233-251, 2015, p. 246.

${ }^{7}$ QUILES, M. I. ““'Mansidão de fogo”: aspectos etnopsicológicos do comportamento alcoólico entre os Bororo". In: SOUZA, M. L. P. (org.). Processos de alcoolização indígena no Brasil: perspectivas plurais. Rio de Janeiro: Fiocruz, 2013, p. 66.

${ }^{8}$ Comissão Construtora de Linha Telegráficas no Estado de Mato Grosso. Relatório Geral apresentado ao Snr. General Diretor Geral de Engenharia Modestino Augusto de Assis Martins pelo chefe da comissão
} 
rio Xingu. Bastante presentes nas fontes oitocentistas associadas ao Mato Grosso, os Bororo teriam sido classificados, por viajantes e escritores, como Bororo Ocidentais - Cabaçais e da Campanha - ou Bororo Orientais - Coroados. Historiograficamente, aqueles que viviam nos sertões na bacia do Rio São Lourenço passaram a ser chamados de Coroados e os que habitavam a região do alto Paraguai passaram a ser nomeados de Cabaçais e Bororo da Campanha. ${ }^{9}$

Não há evidências, contudo, de que se trate intrinsecamente de grupos distintos. Como informa Almeida, ${ }^{10}$ mesmo os cientistas que estiveram na região no final do XIX não foram unânimes em reconhecer identidades distintas entre os Bororo: Julio Koslowsky e Karl von den Steinen, por exemplo, não encontraram características culturais diferenciadoras dos dois subgrupos do oeste, atendo-se às diferenças destes em relação aos Coroados. "O diagnóstico linguístico mostra, sobretudo graças às anotações de Natterer, que a subdivisão atual vigente é meramente geográfica, e não linguística nem cultural". ${ }^{11}$ Membro da comunidade Bororo, Felix Adugoenau, ao ser questionado se os Bororo Ocidentais e Orientais se reconhecem enquanto parte do mesmo grupo, esclarece que os Bororo se reconhecem através da linhagem matrilinear, sendo-lhes irrelevante a localização geográfica. ${ }^{12}$

Para efeito do presente texto, contudo, cabe apelar ao critério geográfico para identificar devidamente os sujeitos da história. Os Bororo Ocidentais, um dos grupos mais populosos do Pantanal Norte no início do século XIX, foram descritos como completamente aculturados pelo antropólogo Vicent Petrullo que os visitara em 1931 em Descalvados, ${ }^{13}$ o que contribuiu para a falácia de sua extinção. Dessa maneira, apesar da presença contínua dos Bororo nos limites setentrionais do Pantanal, não há terras indígenas demarcadas. Ao invés, a propriedade sobre grande parte de seu território foi concedida ao uruguaio Jaime Cibils Buxareo, como veremos a seguir. ${ }^{14}$

\footnotetext{
Major Candido Mariano da Silva Rondon (1900-1906). Disponível em: Arquivo Histórico do Exército (AHEX). ${ }^{9}$ ZAGO, L. Etnohistória Bororo: contatos, alianças e conflitos (século XVIII e XIX). Dissertação (Mestrado em História) - Universidade Federal de Mato Grosso do Sul, Dourados, 2005.

${ }^{10}$ ALMEIDA, M. A. "Índios fronteiriços": a política indigenista de fronteira e políticas indigenistas na Província de Mato Grosso entre a Bolívia e o Paraguai (1837-1873). Porto Alegre: UFRGS, 2013.

${ }^{11}$ FEEST, C. Bororo: a joia da coroa para a antropologia. In: Além do Brasil, Viena, Museu de Etnologia, p. 81-84, 2012, p. 83.

${ }^{12}$ ADUGOENAU, F. Entrevista para Alexia Shellard. 25. Jul. 2019.

${ }^{13}$ FEEST, op. cit.

${ }^{14}$ Nos referimos à propriedade em sua acepção moderna: alienável, absoluta, exclusiva. Difere-se, portanto, das sesmarias enquanto concessões, em teoria, condicionais.
} 
Desde o século XVIII, os Bororo, ${ }^{15}$ assim como os Guatón ${ }^{16}$ e os Chiquitano, ${ }^{17}$ vinham enfrentando a ocupação de suas terras por colonos luso-brasileiros. A família Pereira Leite invadiria, ao longo do século XIX, vastas áreas indígenas em torno do alto Paraguai, tendo aval da Coroa e do Império para matar e aldear as populações locais nesse percurso. A partir da Fazenda Jacobina, localizada na margem esquerda do rio Paraguai, nos arredores de Vila Maria atual Cáceres -, os Pereira Leite avançaram em direção sudoeste, alcançando terras bolivianas. Fundaram fazendas como Descalvados e Cambará, buscando consolidar seus domínios através do gado bovino.

Os Bororo resistiram e continuaram vivendo no alto Paraguai, mantendo aldeias em Cambará, em San Matias, e em outros sítios; alguns trabalhavam para os Pereira Leite e outros fazendeiros da região, enquanto outros refugiavam-se em campos e matas. A geografia movente dos Bororo permitia-lhes permanecer nesses territórios tradicionais movediços, vivendo sobretudo de pesca e caça. As inundações restringiam os movimentos colonizatórios, empurrando o gado e seus exploradores para os campos secos. ${ }^{18}$

O fim da Guerra do Paraguai e o franqueamento do rio homônimo, porém, acelerariam a integração das porções setentrionais da bacia Platina ao sistema-mundo. Empresas oriundas de países como França, Inglaterra, Bélgica e Estados Unidos agora exportavam seu capital para garantir "o controle das fontes de matérias-primas por meio de seus trustes e cartéis, na periferia do mercado mundial". ${ }^{19}$ Um número considerável de forasteiros, especialmente

\footnotetext{
${ }^{15}$ Sobre os contatos, alianças e conflitos interétnicos mantidos pelos Bororo nos séculos XVIII e XIX, cf. ZAGO, op. cit.

${ }^{16}$ Os Guató ocupam as margens do alto Paraguai e de seus tributários desde a chegada dos primeiros espanhóis. São canoeiros que se organizam em torno de núcleos famíliares estendidos. Sobre questões de identidade do tempo presente, cf. LEITE, E. F. e OLIVEIRA, J. E. "Faço parte da história desse jeito!": componentes da memória e da identidade de uma indígena guató. Tellus, Campo Grande, ano 12, n. 23, p. 127-146, jul./dez. 2012.

${ }^{17} \mathrm{O}$ termo Chiquitano foi cunhado por espanhóis que o utilizavam para referir indiscriminadamente indígenas habitantes das margens do alto Paraguai e do Guaporé. Em fins do século XVII, missões jesuítas passaram a congregar esses diferentes grupos, incluindo Bororo, em aldeamentos religiosos. (COSTA, J. E. F. M. A coroa do mundo: religião, território e territorialidade Chiquitano. Cuiabá: EDUFMT, 2006). Habitando uma área que foi inicialmente atribuída à Coroa espanhola, os Chiquitano são, por vezes, considerados bolivianos. Essa classificação é, por vezes, mobilizada por políticos e fazendeiros na disputa por terras indígenas. Cf. SILVA, J. F. Identidades e conflito na fronteira: poderes locais e os chiquitanos. Memoria americana, v. 16, n. 2, p.144-145, 2008. Disponível em: <http://www.scielo.org.ar/pdf/memoam/n16-2/ n16-2a01.pdf>. Acesso em 13 jun. 2020.

${ }^{18}$ Desde o século XVI, os colonos ibéricos vinham trazendo vacas e bois para sustento de suas povoações ao longo do Paraguai. Entre guerras, conflitos e correrias, os animais se dispersavam pelas extensas pastagens nativas. (CORRÊA FILHO, V. Monografias cuiabanas. Cuiabá: IHGMT, 2002).

${ }^{19}$ TRUBILIANO, C. A. B. No rastro da boiada: pecuária e ocupação do sul de Mato Grosso (1870-1920). Revista
} 
dos países banhados pelos tributários do Rio da Prata, se dirigiram ao Mato Grosso em busca de terra, trabalho e riqueza. Também afluíam trabalhadores de outras províncias brasileiras, vindos ou trazidos para atender às novas demandas laborais.

O Recenseamento de 1872 contabilizou na província a população total de 60417 pessoas, sendo 1651, ou 2,73\%, originários de outras províncias brasileiras, e 1669 , ou $2,76 \%$, oriundos de outros países. ${ }^{20}$ Dos 1669 estrangeiros, eram 655 africanos (dos quais apenas 295 eram livres), 369 europeus e 645 platinos (306 paraguaios, 174 bolivianos, 80 argentinos e 83 orientais - como eram chamados os uruguaios no período). ${ }^{21} 71 \%$ dos forasteiros brasileiros e $65 \%$ dos estrangeiros eram do sexo masculino, mas é importante destacar que, entre todas as nacionalidades, as mulheres são minoria, embora entre europeus, argentinos e uruguaios, estejam presentes em menor proporção, cerca de $7 \% .^{22}$

A composição populacional indica um significativo fluxo de pessoas ao longo da bacia Platina nos anos 1870. Mato Grosso passara a atrair imigrantes, sobretudo homens, em busca de trabalho e oportunidades de negócios. Como aponta Jesus da Silva Brandão, o comércio de mercadorias tornara-se convidativo a empresários estrangeiros como Jaime Cibils Buxareo, que já nos anos 1870, passara a transacionar produtos entre os portos de Corumbá, Montevidéu e Buenos Aires. ${ }^{23}$

Em 1881, por ocasião da morte de João Carlos Pereira Leite, a notícia da venda de suas sesmarias, despertou o interesse de Cibils, que acompanhado de seu colaborador, o químico francês Émíle Soulez, embarcou em uma viagem para reconhecer a potencialidade das terras à venda.

Uruguaio de origem catalã, habitante de Buenos Aires e empresário no ramo de carne bovina, Cibils chegou a Mato Grosso em agosto do mesmo ano. ${ }^{24}$ Da fazenda Descalvados empreendeu, por alguns dias, uma expedição a cavalo

Crítica Histórica, Maceió, n. 9, p. 174-196, 2014, p. 186.

${ }^{20}$ Estima-se que nesse número de 60417 não estavam incluídas as populações quilombolas e indígenas livres.

${ }^{21}$ São incluídos bolivianos nessa conta, já que também a Bolívia é banhada por tributários do Prata. (Recenseamento Geral do Brasil em 1872, p. 140. Disponível em: https://biblioteca.ibge.gov.br/visualizacao/ monografias/GEBIS\%20-\%20RJ/Recenseamento_do_Brazil_1872/Imperio\%20do\%20Brazil\%201872.pdf).

${ }^{22}$ De todos os europeus, apenas entre ingleses, a população feminina é maior: 7 mulheres e 5 homens.

${ }^{23}$ BRANDÃO, J. S. Cuiabá: desenvolvimento urbano e socioeconómico (1825-1945). Cuiabá: Livro mato-grossense, 1991.

${ }^{24}$ MARIANI, A. Una aventura industrial: los negócios de estancia y saladero de Jaime Cibils Buxareos en Mato Grosso, 1881". In: Terceras Jornadas de Historia Económica, jul. 2003, Montevidéu. Anais eletrônicos... Disponível em: < http://www.audhe.org.uy/jornadas/internacionales/terceras-jornadas-de-investigacion-2003.html>. 
acompanhado do francês e de homens não-identificados. Deixou registradas suas impressões em um diário de viagem, assinalando em seus escritos, a presença de moradias indígenas, assim como a "imelhorável" orientação de um guia indígena chamado Sebastián. ${ }^{25}$

Cibils encontrou bons pastos, planícies férteis e abundância de árvores, tendo considerado o gado "muito lindo e de bom corpo mas bastante magro". ${ }^{26}$ Ainda assim, considerou regressar a Buenos Aires sem efetuar a compra, preocupado com as dificuldades que poderiam estorvar o negócio: a imprecisão de limites territoriais entre Brasil e Bolívia, a itinerância e alegada indolência das populações locais, a violência costumaz e o abuso das autoridades. ${ }^{27}$ Soulez o dissuadiu, calculando um prognóstico vantajoso e lucrativo para a moderna indústria que construiriam naquelas terras. Esse empreendimento possibilitaria ampliarem a capacidade exportadora de conservas de carne da marca Cibils y Soulez, que até então, eram processadas na fábrica La Conserva - consórcio entre Souléz e as casas Cibils e Dickinson - em Salto, no Uruguai . ${ }^{28}$

Cibils arrematou a Fazenda Cambará, compreendendo a totalidade das terras do major Pereira Leite localizadas na margem direita do rio Paraguai entre o rio Jauru ao norte, e a lagoa Uberaba ao sul - por $557.572 \$ 800$ réis..$^{29} \mathrm{~A}$ compra, acordada para um pagamento à prazo que expiraria em 40 meses, foi intermediada por Mattos \& Cia, casa comercial de importação e exportação em Corumbá. ${ }^{30}$

O empresário uruguaio também comprou do argentino Rafael Del Sar uma sesmaria nas proximidades do Morro Descalvado, encrustada nas terras de Pereira Leite. Del Sar a adquirira do próprio major Pereira Leite na década de 1870 para montar uma charqueada. ${ }^{31}$ A fazenda de Cibils, englobando dezenas de sesmarias, seria nomeada Descalvados, pois, após cogitar construir a sede do empreendimento nas margens da Lagoa Uberaba, o empresário

\footnotetext{
${ }^{25}$ CIBILS apud Ibidem, p. 14. Tradução livre da autora: "inmejorable".

${ }^{26}$ CIBILS apud Ibidem, p. 14. Tradução livre da autora: "muy lindo y de buen cuerpo pero bastante flaco". ${ }^{27}$ Ibidem.

${ }^{28}$ MENANTEAU, L. e BORETTO, R. Le patrimoine culturel et industriel du bas-Uruguay (Argentine, Uruguay): typologie, spécificités et potentialités touristiques. Nantes: Université européenne d'été Val de Loire, 2007.

${ }^{29}$ GARCIA, D. S. C. Territórios e negócios na "Era dos Impérios": os belgas na fronteira oeste do Brasil. Brasília: FUNAG, 2009, p. 91.

${ }^{30}$ CARTÓRIO do 20 Ofício, livro de registros, Cáceres, 15 de setembro de 1881apud GARCIA, D. C. C. Op. Cit. p. 91. Mattos \& Cia chegaria ao século XX como uma das casas comerciais mais ricas da província de Mato Grosso.

${ }^{31}$ GARCIA, op. cit, p. 88. No Mappa geografico da $3^{\text {a }}$ partida de divizõens q comprende do Salto Grande do Parana the aboca do rio Jaurú, de 1754, esse morro é identificado como Morro do Escalvado, tendo no século XIX sido renomeado como Descalvado.
} 
acabou optando por estruturar na rústica charqueada, a moderna indústria de derivados de carne que se tornaria uma das maiores iniciativas capitalistas do Mato Grosso, na virada do século XIX-XX.

No âmbito da indústria pecuária platina, a fazenda em Cáceres, no alto Paraguai, apresentava a desvantagem de localizar-se a mais de 3000 quilômetros dos portos de Buenos Aires e Montevidéu, dificultando o acesso a máquinas, insumos e consumidores. Todavia, alguns dos ramos empresariais explorados pela família Cibils, como mencionado anteriormente, eram transportes e infraestruturas fluviais, além de comércio. ${ }^{32}$

A fazenda situava-se em uma área estratégica no que tange ao desenvolvimento econômico do interior da América do Sul. Além de oferecer possibilidades de conexão entre a Bolívia e o Atlântico através das lagoas Uberaba, ${ }^{33}$ o rio Jauru, que demarcava limite norte da fazenda, era uma das principais vias de acesso entre as bacias Platina e Amazônica. Após seu percurso e de seu tributário Aguapeí, poucos quilômetros restavam para aceder ao rio Alegre, tributário do Guaporé e, portanto, pertencente à Bacia Amazônica.

As circunstâncias ecológicas do Pantanal também facilitavam a criação de bovinos. Nas épocas de vazante, o solo era enriquecido pela decomposição da matéria orgânica trazida pelas cheias, o que nutria as gramíneas das margens do Paraguai. Além disso, as doenças tropicais da Amazônia pouco incidiam na região, tendo o gado se multiplicado, espalhado e asselvajado, desde sua introdução por colonos ibéricos a partir do século XVI. Originou-se assim o gado pantaneiro, resistente aos mosquitos e às cheias e vazantes sazonais. ${ }^{34}$

Por conseguinte, os rebanhos de Descalvados eram abundantes e adequados aos processos produtivos saladeiros, com carnes rijas e pouco gordurosas, e couros muito resistentes. A fazenda possuía centenas de milhares de vacas e bois, estimados por Cibils entre 150 a 180 mil cabeças, ${ }^{35}$ embora

\footnotetext{
${ }^{32}$ Em meados do século XIX, a família Cibils possuía uma frota de fragatas e buques que empreendiam comércio entre América (Cuba, Brasil, Argentina e Uruguai) e Europa. Também foi responsável por construir em Montevidéu, em consórcio com Juan Jackson, o dique Cibils-Jackson (hoje Dique Nacional) que, inaugurado em 1879, tornou-se um dos mais importantes da América do Sul no período. (MARAN, J. Reseña histórica del dique de la Armada. In: Ciclo de Conferencias de Fundación Histarmar, Buenos Aires, 2003. Disponível em: <https://www.histarmar.com.ar/AcademiaUruguayaMyFl/2003/DiqueArmada.htm>).

${ }^{33}$ É interessante destacar que, ainda hoje, estuda-se a possibilidade de conectar o oriente boliviano ao oceano Atlântico através das Lagoas Uberaba, Gaíba e Mandioré. (ZUGAIB, E. A hidrovia Paraguai-Paraná. Brasília: FUNAG, 2006).

${ }^{34}$ CORRÊA FILHO, op. cit.

${ }^{35}$ MARIANI, op. cit., p. 12.
} 
outros como Pimenta Bueno, em 1880, ${ }^{36}$ e Cândido Rondon ${ }^{37}$ e Corrêa Filho, ${ }^{38}$ décadas mais tarde, tenham asseverado a existência de mais de 600 mil reses naqueles campos na época de Pereira Leite. ${ }^{39}$ Se este número aparenta estar superestimado, os números de Cibils, por sua vez, teriam sido rebaixados, como revela o próprio empresário, numa presumível estratégia de negociação do preço da fazenda. ${ }^{40}$

Segundo Rondon, a população bovina da fazenda Descalvados havia sido, em grande parte, angariada da Fazenda Caiçara durante o período Imperial, o que teria concorrido para seu total esvaziamento: esta chegaria ao século XX sem "um só rez, tendo sido todo o gado roubado pelos fazendeiros circunvizinhos, brasileiros e bolivianos". ${ }^{41}$ Descontando a falta de rigor historiográfico de Rondon, é plausível afirmar que as Fazendas Reais Caiçara e Casalvasco - fundadas, em fins do século XVIII, próximas a Vila Bela e Vila Maria, para abastecer as zonas mineradoras e fronteiriças do oeste do Brasil tenham fornecido parte do gado que se propagou nos campos do alto Paraguai. Porém, isso não teria ocorrido apenas em função de roubos, mas também por fugas, afinal, as cercas apenas se disseminariam nas fazendas mato-grossenses a partir do século $\mathrm{XX}^{42}$

Nos planos e estudos elaborados a partir de sua viagem a Descalvados em 1881, Cibils, considerara adequada a qualidade das pastagens, "em sua maioria maciegas e espécies de gramíneas e capim-rabo-de-raposa que come bem o gado". Desse modo, ele não apresenta ideias de benfeitorias nesse quesito, salvo um projeto de construir pequenos diques para assegurar um fluxo de água constante, especialmente nos lotes mais suscetíveis às mudanças de estação. ${ }^{43}$ Ao garantir acesso a água e minimizar a extensão das cheias, $o$

\footnotetext{
${ }^{36}$ BUENO, F. A. Memória Justificativa dos trabalhos de que foi encarregado à província de Matto Grosso, segundo instruções do Ministério da Agricultura de 27 de maio de 1879. Rio de Janeiro: Typographia Nacional, 1880.

${ }^{37}$ Comissão construtora de linhas (...), op. cit., p. 183.

${ }^{38}$ CORRÊA FILHO, op. cit.

${ }^{39} \mathrm{~A}$ informação primária provinha de Pimenta Bueno, tendo sido reproduzida por Rondon - sem menção ao autor original - e Corrêa Filho que, todavia, alude ao exagero no número do engenheiro militar mato-grossense.

${ }^{40}$ CIBILS apud MARIANI, op. cit., p. 14.

${ }^{41}$ Comissão construtora de linhas (...), op. cit., p. 128.

${ }^{42}$ WILCOX, R. "Cattle and environment in the pantanal of Mato Grosso, Brazil, 1870-1970". Agricultural History, Kennesaw, v. 66, n. 2, p. 232-256, 1992.

${ }^{43}$ CIBILS apud MARIANI, op. cit.., p. 12. Tradução livre da autora: "en su mayoría maciegas y espécies de gramilla y cola de zorra que come bien el ganado".
} 
empresário pretendia amansar o gado, fixando-o em locais determinados, o que possibilitaria a exploração, não apenas de carne e couro, mas também de leite.

Sem grandes cuidados em relação à reprodução e alimentação, no Pantanal, em geral, e em Descalvados, em particular, a pecuária foi estruturada em moldes extrativistas, até o primeiro quarto do século XX. Nas palavras de um produtor do período, "lá não se criava gado, mas colhia-se gado" Segundo informantes do período, como Rondon, ${ }^{45}$ a administração de Cibils manteve a reprodução e alimentação espontânea.

\section{A mercantilização dos sertões}

Entre 1875 e 1878, o médico e militar João Severiano da Fonseca (patrono do Serviço de Saúde do Exército Brasileiro) percorreu a Província de Mato Grosso como integrante da Comissão de Demarcação dos Limites entre o Brasil e a Bolívia. Em seu diário de viagens, registrou suas impressões em relação ao traquejo cultural dos habitantes de San Matias:

O povo de S. Matias fica a sete quilômetros e meio da Corixa do Destacamento. É uma pequena povoação de mais ou menos duzentas almas, índios quase todos chiquitanos, e alguns bororos. Compõe-se, como todas as missões jesuíticas, de uma praça retangular, tendo numa das faces a igreja e nas outras as habitações. (...) São estas bandas povoadas pelos restos das nações dos chiquitos e bororós, aldeados outrora pelos jesuítas espanhóis. S. Matias é toda de chiquitanos. Os homens, conquanto andem inteiramente à vontade entre os seus, quando saem para os povoados vestem camisa, calça e chapéu, senão também a sua jaqueta, trazendo sempre na cintura uma banda ou faixa vermelha muito apreciada em todos os países castelhanos, e aqui por tal forma, que dir-se-á usarem de calças só para terem o prazer de lhe passarem a cinta. Uma faca de ponta ou um facão é complemento obrigatório do traje de viagem. (...) Falam estas gentes mais ou menos quatro idiomas: o chiquitano, o bororo, o espanhol e o português. Ora, de um povo, que dispõe assim de tão vastos conhecimentos linguísticos, longe deve ir a ideia de dizê-lo curto de civilização. ${ }^{46}$

Assim como San Matias, Cáceres também era povoada por indígenas. Em sua ata de fundação em 1778, Vila Maria do Paraguai contabilizava 78 indígenas provenientes das fronteiras espanholas, entre os seus 161 habitantes,

\footnotetext{
${ }^{44}$ MACIEL, J. B. A pecuária nos pantanaes de Mato Grosso: these apresentada ao $3^{\circ}$ Congresso de Agricultura e Pecuária. São Paulo: Imprensa Methodista, 1922. P. 18.

${ }^{45}$ Comissão construtora de linhas (...), op. cit.

${ }^{46}$ FONSECA, J.S. Viagem ao redor do Brasil: 1875-1878. Rio de Janeiro: Typografia de Pinheiro, 1880, p. 360-364. Disponível em: <https://www2.senado.leg.br/bdsf/item/id/242429>.
} 
dos quais brancos eram apenas por volta de $11 .{ }^{47}$ Portanto, cerca de $93 \%$ da população que formara Vila Maria era indígena, misturada também com africanos e descendentes. Como reafirma Hercules Florence, em viagem a Vila Maria 50 anos depois de sua fundação, a população da cidade compunha-se de "seis ou sete homens brancos, trezentos caburés descendentes de índios aldeados no tempo de D. Maria I, mulatos e negros". ${ }^{48}$

As fazendas fundadas no entorno dessas duas povoações dependeram invariavelmente de trabalho indígena, sobretudo de Bororo e Chiquitano. Embora parecesse haver preferência dos fazendeiros por trabalhadores Chiquitano, percebidos como mais disciplinados, os Bororo, sendo provavelmente o grupo mais numeroso da região, foram bastante impactados.

A fazenda de Pereira Leite foi formada, no início do século XIX, sobre território Bororo, através de extermínio e escravização. Conforme relatado por Florence, o próprio coronel revelara o assassinato de centenas de Bororo e a escravização dos sobreviventes. ${ }^{49}$ Já no século XXI, pesquisadores identificaram nos povoados da região, como Porto Limão, nas margens do rio Jauru, indivíduos que se autodesignam como descalvadianos. Nascidos na área da fazenda, descendentes de Guató, Chiquitano, e sobretudo Bororo atribuem a si próprios o gentílico descalvadiano, não para negar sua origem indígena, mas para enfatizar sua ascendência local, sem incorrer nos perigos de se declararem índios. ${ }^{50}$

Maus-tratos, torturas e assassinatos têm sido um padrão recorrente imposto aos indígenas no alto Paraguai. Tendo passado por diferentes senhores e proprietários, de Pereira Leite no século XIX, a Luiz Lacerda nos anos 1940, Descalvados registra um histórico de decepações, mortes e injustiças que perpassa toda a modernidade. ${ }^{51}$ Orelhas cortadas, ${ }^{52}$ rostos sem narizes, mãos sem dedos, estupros coletivos, espancamentos, são barbaridades que surgem em diversas narrativas, de Koslowsky (naturalista que visitou a região

\footnotetext{
${ }^{47}$ ATA DE FUNDAÇÃO DE VILA-MARIA DO PARAGUAI apud MENDES, N. F. História de Cáceres: história da administração municipal. $2^{\mathrm{a}}$ ed. Cáceres, MT: Editora UNEMAT, 2009.

${ }^{48}$ FLORENCE, H. Viagem fluvial do Tietê ao Amazonas de 1825 a 1829. Brasília: Senado Federal, Conselho Editorial, 2007, p. 181.

${ }^{49}$ Ibidem.

${ }^{50}$ PÉCLAT, G. T. S. C. Descalvados: a carne de charque em projetos de memória e de identificação de um grupo de trabalhadores (Pantanal, MT, 1995-1990). Tese (Doutorado em História) -Universidade de Brasília, Brasília, 2011.

${ }^{51}$ Recentemente, em trabalho de campo no ano 2018, ouvi denúncias de trabalhadores que não receberam salário por 9 meses. Ademais só tinham permissão para deixar a propriedade uma vez por mês.

${ }^{52}$ PÉCLAT, op. cit.
} 
nos anos 1890) ${ }^{53}$ e Dionant (administrador da fazenda entre 1895 e 1904) ${ }^{54} \mathrm{a}$ relatos orais proferidos por descalvadianos no século XXI. ${ }^{55}$ Informantes também indicam que houveram tentativas recorrentes de ocultação dos indícios da presença indígena no território de Descalvados: queima de documentos, destruição de marcos, cobrimento vegetacional de covas funerárias, além de muitos assassinatos. ${ }^{56}$

Os Bororo, entre outros grupos indígenas habitantes da fronteira oeste, foram particularmente afetados pelos projetos modernizadores que, na segunda metade do século XIX, associaram Estado brasileiro e corporações capitalistas no movimento de incorporação de territórios selvagens ao sistema-mundo. Mudanças econômicas, ecológicas, políticas e cosmológicas foram violentamente impostas às comunidades locais por meio de forças armadas privadas e militares. Embora tenham logrado manter redes de contatos autônomas, Bororo, Chiquitano, Guató, e até brasileiros, bolivianos e quilombolas, tiveram seus circuitos de mobilidade e interação bastante constrangidos. ${ }^{57}$

Vapores e expedições cruzando os rios e os sertões eram cada vez mais recorrentes. Os Coroados, fugindo de missionários, buscaram caminhos ao norte para se internar "de mais a mais ao fundo das matas". ${ }^{58}$ Os Guató migraram rio Paraguai acima, visando escapar da Guerra do Paraguai, tendo posteriormente rumado ao sul, para fugir da Companhia Cibils. Os Bororo ditos Ocidentais tiveram que enfrentar vários ataques empreendidos para reduzi-los em aldeamentos, tendo parte significativa de sua população sido dizimada.

\footnotetext{
${ }^{53}$ KOSLOWSKY, J. Algunos datos sobre los Indios Bororós. Revista del Museo de La Plata VI, La Plata, p.375-41, 1895. Disponível em: <https://publicaciones.fcnym.unlp.edu.ar/rmlp/article/view/1141/1238>.

${ }^{54}$ DIONANT, F. Le Rio Paraguay \& l'État Brésilien de Matto-Grosso. Bruxelles: L'Imprimerie Nouvelle, 1907. (Publication de la Société Belge d'Etudes Coloniales). Koslowsky e Dionant atribuem às onças, a mutilação de dedos, mãos e narizes de homens Bororo, mas alguns indícios desacreditam essa versão. Dionant menciona que o mesmo não acontece aos Guatós, ainda que estes usem azagaias e aqueles, armas de fogo. Cabe mencionar que o belga enaltece o respeito à propriedade demonstrado pelos Guató, contrapondo-os aos Bororo. Além disso, os felinos costumam atacar pescoços e crânios e não membros.

${ }^{55}$ PÉCLAT, G. T. S. C. "Fotografias e emoções: saudades e esquecimentos”. Textos e Debates, Boa Vista, 2013, n. 20, pp. 22-38.

${ }^{56}$ PÉCLAT, Descalvados... op. cit. Também ouvi de um informante, em 2018, que recentemente mandaram plantar grama sobre um cemitério de crianças.

${ }^{57}$ Todavia, uma vez que as fontes históricas tradicionais costumam fixar os sujeitos enunciadores da história como homens brancos de origem europeia, as inferências às relações selvagens são indiretas, o que prejudica, de certa maneira, o trabalho historiográfico.
}

${ }^{58}$ DIONANT, op. cit., p. 158. 
Apesar de ter reconhecidamente comandado massacres contra os Bororo, João Carlos Pereira Leite conseguiu tornar-se responsável por aldeamentos indígenas nos arredores de Vila Maria, dirigindo solicitação de verbas ao presidente de província para "comprar-se ferramentas e roupas para os Índios Bororos da Campanha" que "habitam nos campos do Marco, além do rio Paraguai". ${ }^{59}$ Além de demandar financiamento público para exploração de trabalho indígena em seu benefício, Pereira Leite também moveu - ou extinguiu - aldeia dos Bororo Cabaçais, contrariando a negativa de João Baptista de Oliveira, Diretor Geral de Índios. Oliveira vetara seu pedido encaminhado em 1861, por entender que este se opunha à "lei de terras que conformou as posses em que se achavam os índios em suas aldeias ao tempo de sua promulgação e regularizou a ocupação dos terrenos devolutos". ${ }^{60}$

A tática de aldeamento, seguido de remoção e transposição, foi sistematicamente utilizada no Brasil como forma de destituir direitos indígenas e evitar as conformações de posses previstas na lei de terras. Os Pereira Leite souberam utilizar esses estratagemas para consolidar seus direitos possessórios sobre um território Bororo, movendo e removendo aldeias. Porém, a imensidão e diversidade das terras possibilitara a coexistência, ao longo de décadas, de grupos indígenas que lhe prestavam trabalho, e também a outros fazendeiros, e grupos mais autônomos e tradicionais. Portanto, o senhorio sobre as dezenas de sesmarias que haviam sido outorgadas aos Pereira Leite era, em grande extensão, meramente virtual, restringindo-se às cartas jurídicas. Progressivamente, expandiria-se a apropriação efetiva de terras indígenas, especialmente com a chegada de novos agentes dispondo de novas estratégias e tecnologias.

Através do empreendimento Descalvados, dimensionado em cerca de 1 milhão de hectares, ${ }^{61}$ a Companhia Cibils ${ }^{62}$ teria papel fundamental na

\footnotetext{
${ }^{59}$ Livro de Registros da Diretoria Geral dos Índios (1860-1873). Pedindo autorização a presidência para comprar-se ferramentas e roupas para os Índios Bororos da Campanha. (3 de janeiro de 1868). Disponível em: Arquivo Público de Mato Grosso (APMT). Há outras missivas requerendo ferramentas aos índios Bororo que mencionam João Carlos Pereira Leite.

${ }^{60}$ Livro de Registros da Diretoria Geral dos Índios (1860-1873). Resposta da carta de João Carlos Pereira Leite sobre a mudança d'Aldeia dos Bororos. Disponível em: APMT.

${ }^{61}$ Cerca de 30 países do mundo são menores que 1 milhão de hectares. 0 território do Líbano seria o mais próximo em tamanho à Descalvados, equivalendo a cerca de 1.045.200 hectares.

${ }^{62}$ A corporação belga Sociedade Anonyma Compagnie des Produits Cibils (Companhia Cibils), foi formada em Antuérpia para comprar o empreendimento em Mato Grosso, incluindo entre seus acionistas, Jaime Cibils, Auguste Grisar, William Ford Schmoele, Alexis Mols, estando os três últimos comprovadamente envolvidos em empreendimentos colonialistas no Congo. Segundo Rondon, a Companhia era associada ao próprio rei da Bélgica, Leopoldo II (RONDON, C. M. S. The Roosevelt-Rondon scientific expedition and the telegraph line commission. Rio de Janeiro, 1916. Translated by Reidy e Murray. P. 35. Disponível em: <http://
} 
colonização do alto Paraguai, cerceando as potencialidades cosmológicas e epistemológicas locais, explorando animais, homens e mulheres. ${ }^{63} \mathrm{O}$ ritmo do trabalho imposto concentraria grande parte da energia laboral local nas atividades relacionadas à produção de extrato de carne bovina. Contaria para tanto com apoio institucional de agentes públicos, que tanto ansiavam o progresso, como percebe-se no relatório do próprio presidente da província:

(...) não posso deixar de fazer rápida menção do importante estabelecimento de propriedade dos abastados cidadãos (sic) argentinos (sic) Jaime Cibils y Buxareo, situado no município de São Luiz de Cáceres e destinado ao fabrico de extrato de carne e caldo concentrado, que exportam em grande quantidade para os mercados estrangeiros. Consta-me que é uma fábrica em proporções bastante desenvolvidas, empregando máquinas movidas a vapor e numeroso pessoal, que acusam mui avultado capital nela convertido. ${ }^{64}$

Antes de formar a Companhia Cibils, o uruguaio empreendera um longo processo para obter os títulos de propriedade das centenas de lotes que compunham Descalvados, o que finalmente conseguiu em 1896. Declarando posse mansa e pacífica desde $1881,{ }^{65}$ os relatórios entregues ao governo informam a presença de marcos de aroeira nos lotes, confinando posses de exatos 3600 hectares - exatamente como limitara o presidente do estado Manoel José Murtinho. ${ }^{66}$ Os textos dos documentos são muito semelhantes e a grande maioria refere uma "boa casa de morada, ranchos para camaradas, currais de madeira". ${ }^{67}$ Foram elaborados com o objetivo de certificar as condições para efetivação das propriedades, baseadas na Lei no 20 de 9 de novembro de 1892, sem corresponder estritamente aos fatos. Parece bastante improvável que houvesse benfeitorias em cada légua quadrada, como alegado no processo. Ademais, grupos indígenas e quilombolas viviam na região, refutando, portanto, a declaração de posse mansa e pacífica.

\footnotetext{
www.brasiliana.usp.br>. Acesso em 03 jan. 2019).

${ }^{63}$ Sobre cosmologias ameríndias, cf. VIVEIROS DE CASTRO, E. Os pronomes cosmológicos e o perspectivismo ameríndio. Mana, Rio de Janeiro, v. 2, n. 2, p. 115-144, out. 1996. Disponível em: <http://www.scielo.br/ scielo.php?script=sci_arttext\&pid=S0104-93131996000200005>. Acesso em: 25 jan. 2020. Sobre diferentes epistemologias, cf. DESCOLA, Philippe. Beyond nature and culture. Chicago: University of Chicago Press, 2013.

${ }^{64}$ Relatório com que o Sr. Presidente da Província de Mato Grosso, Barão de Batovy, abriu a $1^{a}$ sessão da 25a legislatura da respectiva Assembleia no dia 19 de outubro de 1884, Cuiabá, 1884. p. 71-72. Disponível em: APMT.

${ }^{65}$ Como mencionado previamente, Cibils comprara - irregularmente - sesmarias à Pereira Leite e Del Sar, sendo esta transação de conhecimento público.

${ }^{66}$ MORENO, G. Terra e Poder em Mato Grosso: política e mecanismos de burla (1892-1992). Cuiabá, MT: Entrelinhas/EdUFMT, 2007.

${ }^{67}$ Brochuras de processos: Jaime Cibils Buxareo (BR APMT CROP 007), 1895. Disponível em: APMT.
} 
Os habitantes da área da fazenda, nomeadamente os Bororo, foram semanticamente e materialmente transformados em camaradas, apesar das fartas evidências materiais e documentais que indicam sua habitação contínua dos sertões do alto Paraguai, desde antes da chegada dos portugueses, no século XVIII. Outros indícios apontam também para a exploração de sua mão de obra: a forma circular dos currais de parte dos lotes da fazenda Descalvados é sublinhada, em muitos autores, como indicativo de seus saberes, já que na economia simbólica Bororo, a organização dos espaços obedece a uma lógica circular. Dos cerca de 80 relatórios acessados no Arquivo Público de Mato Grosso, mais de 30 mencionam a forma circular dos currais de madeira, embora apenas o processo da posse Aldeia Velha, refira nomeadamente a etnia dos camaradas: "há uma boa casa de morada, ranchos para os camaradas, que todos pertencem à tribo dos índios Bororos, tem currais de madeira em forma circular, cercados de arame e grande quantidade de gado". ${ }^{68}$

A menção aos camaradas Bororo de Aldeia Velha destaca-se, sendo a única referência, em todos os relatórios do processo de titulação, aos grupos indígenas presentes no território de Descalvados. Algumas hipóteses se vislumbram: manipular o reconhecimento, dificilmente refutável, das comunidades Bororo que habitavam as terras almejadas, abreviando sua população, e, simultaneamente, valorizando o papel da empresa Cibils enquanto realizadora do progresso. Fica patente no artigo de Koslowsky, que visitara Descalvados sob amparo de Cibils, que se pretende divulgar a ideia de ascensão das populações "primitivas" à "civilização" através do trabalho:

Desde que estes territórios foram adquiridos pelo senhor Jaime Cibils Buxareo, há melhorado notavelmente a sorte destes indígenas, pois não lhe incomoda o seu modo de viver, e os que trabalham no campo recebem um bom soldo; ainda alguns, como sendo tapejaras dos campos, ganham de cinquenta a sessenta mil réis por mês e naturalmente recebem também a comida, o que é quase o dobro do que ganha um peão nos mesmos lugares; sem embargo, com estes índios não se pode sempre contar para o trabalho, e se o capataz que lhes manda lhes faz alguma censura ou lhes grita, se afastam à "lagoa" como chamam à sua aldeia, sem tomar a menor nota se há pressa no trabalho, ocasionando às vezes grandes prejuízos ao estabelecimento. ${ }^{69}$

\footnotetext{
${ }^{68}$ Idem.

${ }^{69}$ KOSLOWSKY, op. cit., p. 382. Tradução livre da autora: "Desde que estos territorios fueron adquiridos por el señor Jaime Cibils Buxareo, ha mejorado notablemente la suerte de estos indígenas, pues no se les incomoda en su modo de vivir, y los que trabajam en el campo reciben un buen sueldo; aún algunos, como ser los vaqueanos de los campos, ganan de cincuenta á sesenta mil reis por mes y naturalmente reciben tambien la comida, lo que es casi el doble de lo que gana un peon en los mismos lugares; sin embargo, con estos indios no se puede siempre contar para el trabajo, y si el capataz que les manda les hace algun reproche ó les grita, se alejan á la "lagoa" como llaman á su aldea, sin tomar la menor nota si hay premura
} 
Assim, apesar da presença ancestral Bororo, e de outros grupos indígenas, profusamente registrada no alto Paraguai, as posses de Descalvados foram, em 1896, tituladas em nome de Cibils que, com a anuência do presidente do estado Antonio Corrêa da Costa, fez então "a transmissão total da fábrica dos 'Descalvados' à Companhia belga”. ${ }^{70}$ Após acertar a venda na Europa, o uruguaio fizera um acordo verbal com Corrêa da Costa para postergar o vencimento dos impostos de transmissão de bens, para que antes recebesse os títulos de propriedade. ${ }^{71}$ "Os valores da transação foram declarados ao governo de Mato Grosso em 1.147:250\$000 réis (...) pela fábrica e 90:000\$000 réis (...) pelos 208 lotes de terra", sendo pagos 98:980\$000 réis em impostos, equivalentes a $8 \%$ sobre o valor total da venda, conforme legislação fiscal do Estado de Mato Grosso. ${ }^{72}$

A administração de Descalvados passou então às mãos do militar belga, François Van Dionant. A Companhia Cibils declarou um capital social de 1.236:025\$, tendo, portanto, ocorrido uma significativa valorização da fazenda em pouco mais de uma década. ${ }^{73}$ A Companhia definia como objetivo "a fabricação dos produtos Cibils, do extrato de carne, de caldo, peptonas, carnes salgadas, secas e conservadas, sebo, graxa, couros e tudo quanto diz respeito a esta indústria", podendo também "explorar o subsolo dessas fazendas, procurar minas, explorar os seus productos ou ceder a concessão desta exploração a quaisquer pessoas ou sociedade mediante pagamento, entrada, fôro ou parte de interesse". ${ }^{74}$

Posteriormente, os belgas expandiriam suas operações empresariais na região, comprando, em 1899, a fazenda São José nas margens do São Lourenço, e adquirindo concessões para exploração seringueira nas margens do Guaporé e do São Miguel. Todavia, em 1912, abandonariam o Mato Grosso, vendendo Descalvados e os outros empreendimentos belgas à empresa Brazil Land and Cattle Company, que reunia capitais internacionais sob controle do norte-americano Percival Farqhar.

\footnotetext{
en el trabajo, ocasionando ás veces grandes perjuicios al establecimiento".

${ }^{70}$ ASSUMPTO Cibils: para principiar. O Republicano, Cuiabá, Ano I, n. 18, 12 de jan. 1896, p. 4. Disponível em: <http://memoria.bn.br/pdf/304522/per304522_1895_00018.pdf>. Acesso em 15 fev. 2020.

${ }^{71}$ GARCIA, op. cit., p. 117.

${ }^{72}$ Ibidem, p. 126

${ }^{73}$ BRASIL. Decreto no 2007 de 18 de abril de 1895. Concede autorização à Sociedade Anonyma Compagnie de Produits Cibils para funcionar no Brasil. Disponível em: <http://www2.camara.leg.br/legin/fed/decret/1824-1899/decreto-2007-18-abril-1895-525209-norma-pe.html>.

${ }^{74}$ Idem.
} 


\section{A imposição do trabalho}

O gado representou desde o momento em que se disseminou nos pantanais, uma ameaça à ordem social Bororo e a outras comunidades indígenas, à medida em que concorreu para redução de espaços de matas, empobrecimento do solo, e diminuição das populações de outros animais. ${ }^{75}$ Além disso, em fins do século XIX, a formação de grandes fazendas no Pantanal, a partir do resgate dos bovinos bravios implicaria na massiva servidão e escravização indígena. ${ }^{76}$ Como registrou Koslowsky, muitas vezes os peões morriam no cumprimento de tarefas perigosas:

Durante o tempo seco os jovens Bororos se ocupam nas estâncias com o arreio do gado vacum bravio, que pegam empregando o laço. Sua cavalgadura que manuseiam bem, é então o cavalo ou a mula, indistintamente. Também empregam o laço, aproximando-se muito ao animal que querem aprisionar, o que é bastante perigoso, porque o vacum toma a ofensiva, e matando às vezes muitos cavalos e mulas, e ferindo com frequência gravemente ao ginete. A morte ocasionada por uma cornada não está excluída da sorte do campeiro. ${ }^{77}$

Além de riscos envolvidos na captura dos animais, a imposição de atividades pecuárias roubava o tempo indígena dedicado a práticas e atividades tradicionais, desestruturando comunidades. Segundo a antropóloga Renate Viertler, na cultura Bororo a vaca é enquadrada na mesma categoria que humanos não-indígenas, já que, como estes, também destrói plantações, rouba alimento e pisoteia o solo. ${ }^{78} \mathrm{~A}$ lida indígena com o gado bovino ocorreria quase que exclusivamente em contextos de trabalho. ${ }^{79}$ Importante destacar que, além das tradições que costumavam interditar o consumo de carne bovina

\footnotetext{
${ }^{75}$ VIERTLER, R. Amazônia Brasileira: preâmbulo a uma discussão antropológica da questão indígena. Revista da Universidade de São Paulo, São Paulo, v. 6, p. 98-126, jul./set. 1987.

${ }^{76}$ ESSELIN, P. M. A pecuária bovina no processo de ocupação e desenvolvimento econômico do Pantanal sul-mato-grossense (1830-1910). Dourados: Ed. UFGD, 2011.

${ }^{77}$ KOSLOWSKY, op. cit, p. 382. Tradução livre da autora: "Durante el tiempo seco los jóvenes Bororos se ocupan en las estancias con el arreo del ganado vacuno bravío, que cojen empleando el lazo. Su cabalgadura que manejan bien, es entonces el caballo ó la mula, indistintamente. Tambien emplean el lazo, acercándose mucho al animal que quieren apresar, lo que es bastante peligroso, porque el vacuno toma la ofensiva, y matando á veces muchos caballos y mulas, é heriendo con frecuencia gravemente al ginete. La muerte ocasionada por una cornada no está excluida de la suerte del campero".

${ }^{78}$ VIERTLER, op. cit.

${ }^{79}$ VIERTLER, R. A vaca louca: tendências do processo de mudança sócio-cultural entre os Bororos - MT. Revista de antropologia, São Paulo, v. 33, p. 19-32, 1990. O gado, mesmo sem papel ritualístico, figura na mitologia Bororo, associado aos baraes - termo utilizado para designar colonizadores eurodescendentes -, havendo um mito que conta a origem conjunta de baraes e tapira (termo bororo para o gado bovino). Esse mito parece indicar a coetaneidade da chegada de europeus e bovinos no interior do continente sul-americano, ou, ao menos, em teritório Bororo.
} 
entre Bororo e outros grupos indígenas, na medida em que o gado foi virando símbolo e fonte de riqueza, seu proveito foi sendo proibido aos despossuídos.

Vislumbram-se, assim, conflitos que não apenas se ocasionavam de disputas territoriais, envolvendo também a apropriação e reificação de populações humanas e animais. Dispondo de pesca, caça e plantações, as comunidades locais não se entregaram servilmente ao trabalho para recebimento de salário ou pagamento de dívida. Forças milicianas tiveram que vedar o acesso dessas populações aos recursos necessários para sua sobrevivência. Com conivência de governantes, os empreendedores capitalistas privatizaram largas extensões de terras, estorvando a autonomia daqueles que viviam ancestralmente nesses espaços, como expressa o texto de Dionant:

Eu vivo aqui num país semi-selvagem onde uma placa colorida sobre uma casa faz mais efeito que o mais belo título consular, as autoridades eram nulas aqui, tive que seguidamente defender a golpes de fuzis as três ou quatro centenas de léguas de território da companhia belga de produtos Cibils, e sobretudo, seu gado, eu mesmo organizei para este efeito um pequeno destacamento composto por antigos sub-oficiais do exército belga que fez maravilhas contra os assassinos e saqueadores que tinha por vizinhos tanto em Bolívia quanto em Brasil. O presidente do Estado do Mato Grosso, deplorando a ausência de uma força policial suficiente por seu governo, me autorizou a seguir esse modo sumário de fazer justiça ${ }^{80}$.

Anteriormente, no período da administração de Cibils, não se encontraram referências textuais a milícias particulares em Descalvados, mas há indícios de que a peonagem foi amplamente abusada. Em seu diário de viagem, o uruguaio refere um plano de construir um armazém para atender às necessidades dos trabalhadores.$^{81}$ No mesmo documento, ele exprime a intenção de instituir práticas de controle sobre os corpos dos trabalhadores, através do combate ao consumo de álcool e de carne bovina e da restrição à livre movimentação na fazenda, pretendendo "estabelecer penas severas a todo peão que sem fundado motivo, galope seu cavalo". ${ }^{82}$

\footnotetext{
${ }^{80}$ DIONANT apud STOLS, E. O Brasil se defende da Europa: suas relações com a Bélgica (1830-1914). Boletín de Estúdios Latinoamericanos y del Caribe, Amsterdam, n. 18, p. 57-73, 1975, p. 72. Tradução livre da autora: "Je vis ici dans un pays demi sauvage où une plaque sur une Maison fait beaucoup plus d'effet que le plus beau titre consulaire, les autorités étant nulles ici, j'ai souvent à défendre à coups de fusils les trois à quatre cents lieues de territoire de la compagnie belge des produits Cibils, et surtout ses bestiaux, j'ai même organisé à cet éffet un petit détachement composé d'anciens sous-officiers de l'armée belge qui fait merveilles contre les assassins et maraudeurs que j'ai pour voisins, tant en Bolivie qu'au Brésil. Le Président de l'Etat du Matto Grosso déplorant l'absence d'une force de police suffisante dans son gouvernement m'a autorisé à suivre ce mode sommaire de fair ela justice".

${ }^{81}$ MARIANI, op. cit.

${ }^{82}$ CIBILS apud MARIANI, op. cit., p. 17. Tradução livre da autora: "establecer penas severas a todo peón
} 
Independente de seus discursos antiescravagistas que projetavam mudanças radicais nos métodos de trabalho de Pereira Leite, Cibils condescendera, ao adquirir as terras do sesmeiro, que fossem incluídos na venda, 80 trabalhadores supostamente endividados na administração anterior ${ }^{83}$ Ainda que o empresário se declarasse desfavorável a essa modalidade de trabalho que, em sua próprias palavras, tornava o "peão escravo" e pouco interessado no desempenho de suas tarefas, não há registros de que tenha perdoado as abusivas dívidas. Ao contrário, resolveu instituir um sistema de conta corrente, através do qual, os peões recebiam vales para gastar na casa de comércio no centro da fazenda.

Grande parte desses 80 trabalhadores endividados tinha origem indígena - Chiquitano, Guató e, sobretudo, Bororo. Mesmo assim, não parecem ter sido incluídos na estimativa que o próprio empresário uruguaio calculou em relação aos habitantes indígenas de uma aldeia em Cambará. Escreve Cibils que cerca de 60 homens e mulheres de variadas idades, “(...) de constituição robusta, mas muito preguiçosos e dados a bebida, andam em sua maior parte totalmente desnudos", ${ }^{84}$ manifestando sua concepção dos índios de Cambará: indolentes, alcoólicos e nus. Nos documentos oficiais de $1894-1895,{ }^{85}$ o empresário cala sobre esta comunidade, identificando apenas a etnia de camaradas Bororo de Aldeia Velha, sem mencionar a remanescência de aldeias tradicionais.

Cibils instituiu uma organização social do trabalho que delegava às populações indígenas, paraguaias e despossuídas, os trabalhos mais pesados, enquanto as posições de mando e controle eram exercidas por seus conterrâneos, prioritariamente familiares e amigos eurodescendentes. ${ }^{86}$ Seus primos Ramon Reissig e Salvador Buxareo, ${ }^{87}$ o naturalista Carlos V. Burmeister, ${ }^{88}$ Enrique Bonnecarrére e Ceferino Arioni ${ }^{89}$ foram alguns dos responsáveis por

\footnotetext{
que sin fundado motivo, galope seu caballo".

${ }^{83}$ Ibidem.

${ }^{84}$ CIBILS apud MARIANI, op. cit., p. 10. Tradução livre da autora: “(...) son de constitución robusta, pero muy haraganes y dados a la bebida, andan en su mayor parte totalmente desnudos".

${ }^{85}$ APMT. Brochuras de processos: Jaime Cibils Buxareo (BR APMT CROP 007), 1895.

${ }^{86}$ GARCIA, op. cit.

${ }^{87}$ MARIANI, op. cit., p. 13.

${ }^{88}$ KOSLOWSKY, op. cit., p. 383. Como Koslowsky, Burmeister também foi naturalista viajante do Museu da Prata.

${ }^{89}$ Tendo amealhado capitais consideráveis, após poucos anos em Descalvados, Bonnecarrére e Arioni tornaram-se grandes empresários em Montevideo. (CURI, A. B. "Del "ahorro" a la gran empresa: el caso de Ceferino Arioni”. Espacio industrial. Montevideo, ano 9, n. 284, abr. 2007, p. 44. Disponível em: <http://
} 
funções como gestão de salários e dívidas, gestão dos trabalhadores e gestão da fazenda.

Os belgas perpetuariam a divisão étnico-racial ${ }^{90}$ do trabalho nos seus empreendimentos em Mato Grosso, embora tenham também contratado alguns membros da elite local, como forma de garantir alianças. Dionant logrou ser nomeado vice-cônsul da Bélgica em Descalvados em $1898,{ }^{91}$ acumulando posteriormente o cargo de cônsul do Paraguai, o que lhe teria facilitado a cooptação de trabalhadores paraguaios. ${ }^{92}$ Além de Dionant, outros agentes do colonialismo belga em África, como Alexandre Delcommune e José Cousin, vieram investigar os recursos da região, agenciando outros investimentos para os capitais belgas, como a Estrada de Ferro Noroeste do Brasil e a Compagnie des Caoutchoucs du Matto-Grosso..$^{93}$ As corporações belgas compartilhavam cotistas, bancos e gerentes, como Marcuse Parfonry, Borchgrave d'Altena e Clement Laport que trabalharam na administração de ambas, Cibils e Compagnie de Caoutchoucs, além de disporem de antigos oficiais da Force Publique do Estado Independente do Congo e do exército belga.

Em seu livro sobre o rio Paraguai e o Mato Grosso, Dionant emblematicamente intitula um capítulo de População - Mão de Obra,${ }^{94}$ dividindo-o nos subcapítulos: População, Bororos, Guatos, Chiquitanos, Índios Selvagens, Indivíduos de Raça Branca vivendo entre os Índios Selvagens, Peões Paraguaios e Trabalhadores. O belga apresenta números - situando as populações "selvagens" entre 20 e 25 mil e as "mansas", entre 8 e 9 mil-, características - força, índole, inteligência -, habilidades - línguas, lida com gado -, métodos de submissão do trabalho dívida, violência, castigos - e outras informações que considera pertinentes para possíveis investidores. Declara haver na região disponibilidade de mão

www.ciu.com.uy/innovaportal/file/84921/1/revista_final_alta_comprimido.pdf>).

${ }^{90} \mathrm{Cf}$. GROSFOGUEL, R. Para descolonizar os estudos de economia política e os estudos pós-coloniais: Transmodernidade, pensamento de fronteira e colonialidade global. Revista Crítica de Ciências Sociais, Coimbra, n. 80, p. 115-147, mar. 2008,

91 “Em 1897 a legação da Bélgica no Rio de Janeiro solicitou ao governo brasilero a instalação de um consulado daquele país em Descalvados. A solicitação foi negada, mas foi autorizada a instalação de um vice-consulado em Descalvados e seu administrador, o belga François Van Dionant, foi alçado à condição de vice-cônsul". (GARCIA, op. cit., p. 132).

${ }^{92} \mathrm{O}$ autor informa que embora o segundo cargo não tenha sido aceito pelo governo brasileiro, Dionant teria o exercido na prática. (GARCIA, op. cit., p. 176).

${ }^{93}$ Ibidem.

${ }^{94}$ DIONANT, op. cit., p. 149. Tradução livre da autora: “Population - Main-D’Oeuvre”. Na página 34 do mesmo documento, Dionant aconselha aos comerciantes, industriais e financistas que queiram aproveitar esses estudos, para frutífera colocação de seus produtos ou seus capitais, uma visita ao Mato Grosso. 
de obra - "a mão de obra existe no lugar"95 -, afirmando não ser necessário trazer indivíduos de lugares distantes. Logo, o uso de trabalhadores forasteiros, como os cearenses, pode ter sido parte de uma estratégia da Companhia Cibils para miscigenar as populações locais, afastando riscos de reivindicações territoriais indígenas.

$\mathrm{Na}$ literatura historiográfica, identifica-se um intenso fluxo de nordestinos, majoritariamente cearenses, que a partir de meados do século XIX, supostamente fugindo das grandes secas, migraram para o oeste brasileiro no ciclo da borracha. 0 movimento migratório, porém, não foi espontâneo: a maior parte desses nordestinos foi aliciada por paroaras, que publicizavam as possibilidades de enriquecimento, oferecendo-se para financiar as viagens. Os trabalhadores chegavam ao destino com dívidas impagáveis que tendiam a avultar cada vez mais com os preços abusivos cobrados nos armazéns das fazendas. Conjuntamente com os paroaras atuava o Estado, que passou a subsidiar passagens, especialmente no bojo das severas estiagens que se abateram nos sertões nordestinos nos anos 1877-1879. Assim, ao mesmo tempo em que contribuía para o alívio de tensões sociais no Nordeste, a exportação de trabalhadores para o oeste proporcionou a formação de uma reserva de mão de obra, viabilizando maior opressão sobre os despossuídos.

A extensão dos maus tratos praticados aos trabalhadores da Cibils ainda são desconhecidas em seus detalhes, mas as evidências apontam para uma intensa e cruel exploração da mão de obra, sendo importante relembrar que os belgas acionistas da Companhia Cibils eram também cotistas das companhias colonizadoras que perpetuaram assustadoras barbáries no Congo. ${ }^{96} \mathrm{As}$ perversas práticas desempenhadas chamaram atenção de Rondon que, no percurso da instalação das Linhas Telegráficas, entre 1900 e 1906, identificou sepulturas de cearenses cujas mortes atribuiu à negligência da empresa:

Há mais um rancho defronte dos outros e a seu lado as sepulturas onde foi inumada uma família cearense, que ali morreu à mingua, devido ao egoísmo da companhia belga Cibils, que a abandonou naqueles esmos (...).97

A empresa, especialmente no período sob administração belga, recebeu muitas críticas relacionadas aos métodos de trabalho, sendo, por isso, enviado, em 1910, um fiscal do Governo de Mato Grosso para averiguar as denúncias: João da Costa Garcia indeferiu as acusações, enaltecendo a companhia que,

\footnotetext{
${ }^{95}$ Ibidem, p. 68. Tradução livre da autora: "la main-d'oeuvre existe sur place".

${ }^{96}$ GARCIA, op. cit., p. 144.

${ }^{97}$ Comissão construtora de linhas (...), op. cit., p. 145
} 
segundo seu relatório, teria trazido cerca de 300 famílias de cearenses para trabalhar em Descalvados e em concessões em torno do Guaporé. ${ }^{98}$ Essas centenas de cearenses teriam deixado o trabalho após a crise que se iniciou com os conflitos entre os belgas e Balbino Maciel por territórios caucheiros. ${ }^{99}$ Contudo, o próprio administrador da fazenda dera outra explicação para os cearenses desaparecidos: Dionant alegara terem vindo trabalhar para a Companhia belga, 200 cearenses, acompanhados de suas famílias, o que totalizava cerca de 400 pessoas, porém, a varíola os teria dizimado, sobrevivendo apenas $20{ }^{100}$ Um índice de mortalidade de 95\% aponta sugestivamente para condições de trabalho estafantes.

As evidências, portanto, sugerem práticas de peonagem, associadas a coerção e violência. Na Breve Notícia de 1891, há relatos de uma padaria, um escritório e uma igreja, que embora não configurem indícios assertivos de escravização por dívida, fortalecem a hipótese de contenção dos trabalhadores no interior da fazenda. ${ }^{101}$ Segundo relatos de Koslowsky, à casa de comércio em Descalvados, acorriam não apenas os trabalhadores da fazenda, mas também as mulheres indígenas que viviam nas aldeias da região. A prostituição das mulheres Bororo, referida pelo naturalista, aparece atrelada à peonagem e ao alcoolismo: os Bororo em Descalvados teriam "o costume de oferecer sua mulher a qualquer um de quem espera obter algum benefício". ${ }^{102}$ Dionant confirma o uso de prostituição como método empregado para endividar e sujeitar trabalhadores em Mato Grosso. ${ }^{103}$

\section{Considerações finais}

No Brasil, as elites econômicas e o poder público endossaram um conjunto de práticas que orientou a exploração da natureza através do trabalho de homens e mulheres - principalmente de origem indígena e africana - que, supostamente dotados de culturas inferiores, eram considerados seres mais próximos à natureza. A uma representação da natureza como esfera passiva

\footnotetext{
${ }^{98}$ JOÃO DA COSTA GARCIA apud GARCIA,op. cit., p. 178.

${ }^{99}$ GARCIA, op. cit. Na tese de Garcia, o subcapítulo 5.4 trata dos conflitos entre a Companhia Cibils e seringueiros ligado a Balbino Antunes Maciel.

${ }^{100}$ DIONANT, op. cit.

${ }^{101}$ BARRETO, O. N. Breve noticia sobre a grande propriedade do Descalvado no Estado do Mato Grosso. Gazeta Oficial do Estado de Mato Grosso, Cuiabá,11 de junho de 1891, p. 4. Disponível em: APMT.

${ }^{102}$ KOSLOWSKY, op. cit. 3, p. 83. Tradução livre da autora: "la costumbre de ofrecer su mujer á cualquiera de quien espera obtener algun benefício".
}

${ }^{103}$ DIONANT, op. cit. 
e metaforicamente serva, correspondia uma estrutura social fundamentada na passividade obrigatória do trabalho e na submissão total ao dono da terra. ${ }^{104}$ Nesse sentido, a exploração do trabalho pelo capital era almejada como garantia para o progresso do país.

O estabelecimento do Snr. Jayme Cibils, montado, como se acha, em grande escala, não é simplesmente uma empresa de iniciativa particular e por isso merecedora de toda a simpatia; significa mais, uma poderosa alavanca que forçou as carunchosas portas da rotina, fazendo-as girar sobre seus ferrugentos gonzos, para dar passagem ao progresso. ${ }^{105}$

Em Mato Grosso, a falta de documentos idôneos sobre os trabalhadores fazem difícil uma afirmação incisiva, mas a impressão é que eram considerados recursos descartáveis, acompanhando a mentalidade em relação à borracha, ao gado, à natureza. A opressão sobre determinadas camadas populares retroalimentava-se da espoliação operada sobre certos povos, perpetuando assim uma hierarquia socioétnica. Portanto, ainda que nesse momento, a escolha por trabalhadores braçais não se baseasse estritamente em critérios raciais, as contingências históricas haviam criado um nexo causal direto. Como reconheceu Roger Casement em sua expedição ao Peru:

As expropriações dos índios e a indisfarçada negação de todos os direitos em terras indígenas está na base de todo o sistema de escravidão que sem dúvida existe nestas regiões. Se os índios fossem protegidos em sua propriedade de terras, eles não seriam as fáceis presas que são hoje para o explorador. É o sistema de Leopoldo na África - todo de novo - apenas é original na concepção de propriedade do "Estado" na qual Leopold modelou suas astutas reivindicações em terras no Congo...Se você enraiza os nativos no solo - africanos ou índios, polinésios ou seja qual for o grupo nativo - você os liberta. ${ }^{106}$

Nesse sentido, era importante propagar ideologias positivistas, e evolucionistas, que contrapunham "civilizados" - observadores e respeitadores

\footnotetext{
${ }^{104}$ DA MATTA, R. Em torno da representação da natureza no Brasil: pensamentos, fantasias e divagações. In: BOURG, D. Os sentimentos da natureza. Lisboa: Livraria Clássica, 1993. Embora Da Matta faça referência ao senhor, preferimos o termo dono da terra por se estender ao período pós-colonial.

${ }^{105}$ O INICIADOR. O Iniciador: jornal commercial noticioso e litterario, Corumbá, Ano VI, n. 44, 11 jun. 1882, p. 1. Disponível em: <http://memoria.bn.br/pdf/215163/per215163_1882_00044.pdf>.

${ }^{106}$ ROGER CASEMENT apud SÍOCHÁIN, S. “"'More power to the indians”: Roger Casement, the Putumayo and indigenous rights". Irish Journal of Anthropology, 2011, v. 14, n. 2, pp. 5-12. p. 8-9. Tradução livre da autora: "The expropriation of the Indians and barefaced of all rights in land of the Indians is at the bottom of the whole system of slavery that undoubtedly exists in those regions. If the Indians were protected in their land ownership they would not be the easy prey they are today to the exploiter. It is the Leopold system in Africa - all over again - only it is the great original on which conception of "State" ownership Leopold modelled his astute claims in Congo land... If you root the natives in the soil - African or Indian, Polynesian or whatever band of native he may be - you free him".
} 
das leis, das propriedades e das formalidades - e "selvagens" - idólatras, ignorantes, ladrões e saqueadores. Essa narrativa justificava, de certa maneira, as injustiças que eram perpetuadas contra povos indígenas. Estabelecia-se um sistema de controle que se fundamentava na mercantilização da natureza, genericamente através da monetarização e reificação do trabalho, da terra, da natureza.

Os grupos indígenas em Descalvados foram massivamente mortos e explorados, tendo seus territórios apropriados e devastados sucessivamente por fazendeiros e corporações. Porém, valendo-se de um importante conhecimento ecológico e de uma notável resiliência cultural, reconstruíram elementos materiais e simbólicos de sua vida em pequenas comunidades rurais no alto Paraguai.

Artigo recebido para publicação em 28/07/2020

Artigo aprovado para publicação em 16/11/2020 